\begin{abstract}
مقاله يخووهشى
مجله دانشگاه علوم يزشكى رفسنجان

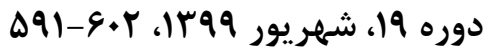

بررسى فراوانى سندرم ساختمان بيمار و عوامل مرتبط با آن در يرستاران بيمارستان

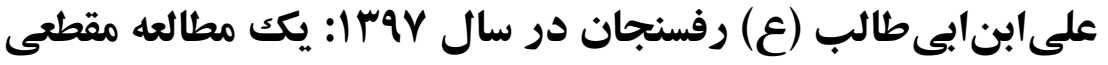

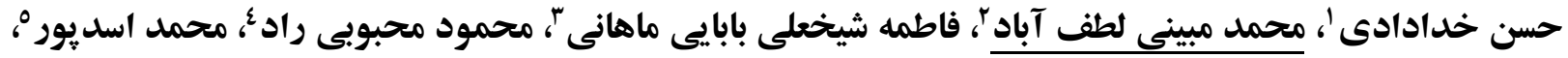

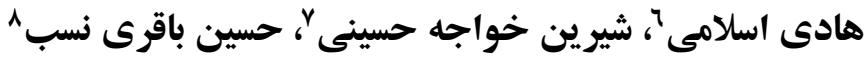

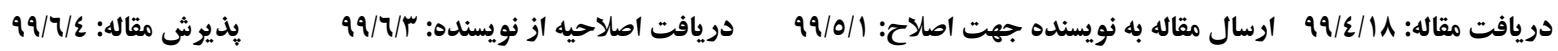

جكيده

زمينه و هدف: سندرم ساختمان بيمار (Sick building syndrome; SBS) يك بيمارى ناشى از ساختمان است كه افراد حاضر در محيط

آن، وضعيت جسمى و روحى مناسبى را تجربه نمى كنند. تغييرات روحى و جسمى شامل سردرد، تهوع، خستگى نامتعارف، عدم تمركز

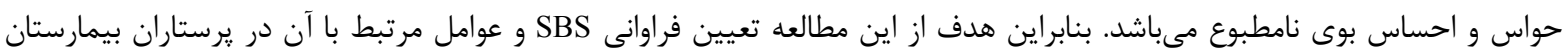

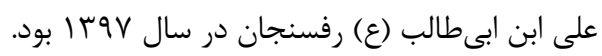

مواد و روشها: اين مطالعه مقطعى با استفاده از يرسشنامه استاندارد MM040EA مرتبط با SBS و كيفيت هواى داخل ساختمان، در

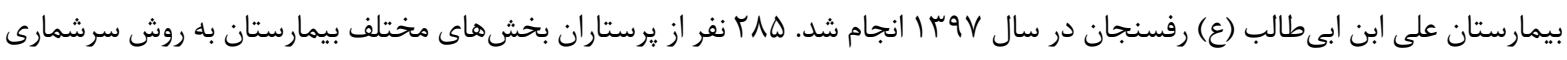

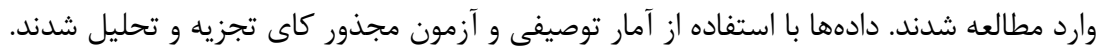

يافته ها: ميانكين و انحراف معيار سن يرستاران شركت كننده • •

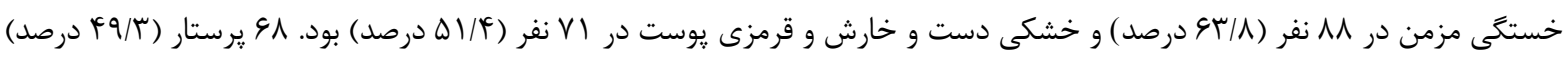

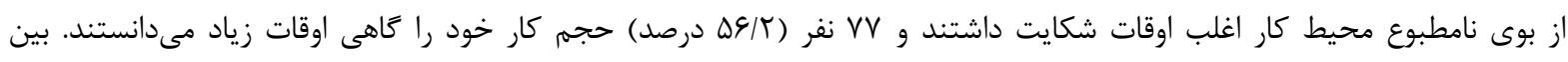

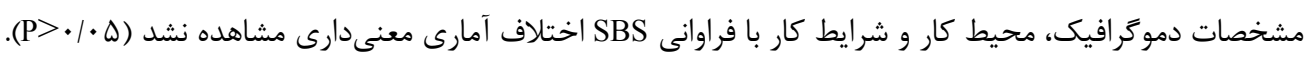

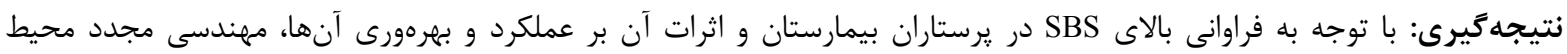

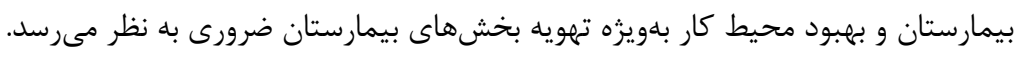
وازههاى كليدى: سندرم ساختمان بيمار، محيط كار، يرستاران، بخشهاى بيمارستان، رفسنجان
\end{abstract}

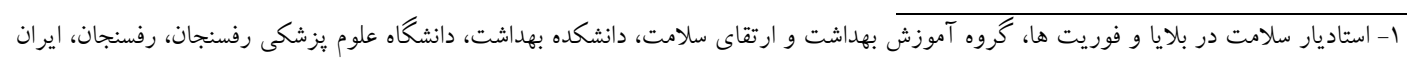

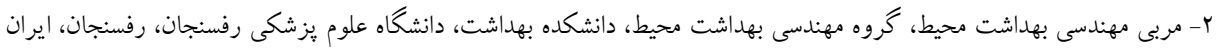

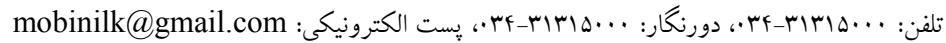

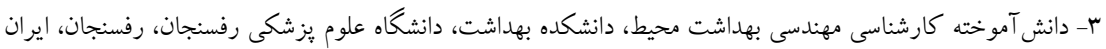

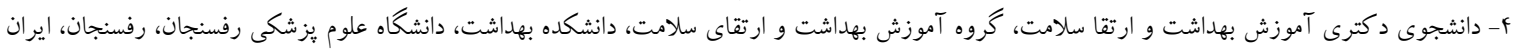

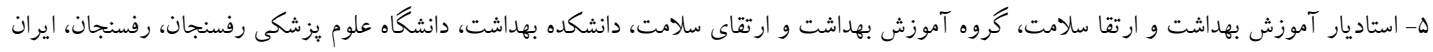

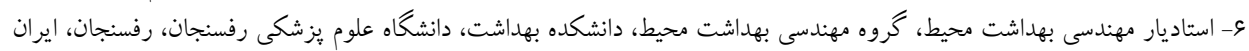

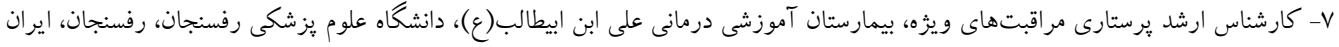

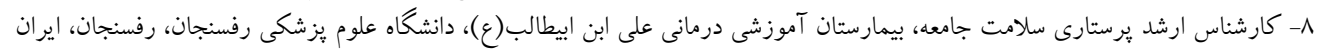


ساختمان شده و بر كيفيت و بهرهورى اثركذار است. داشتن

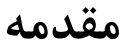

سابقه كارى يك ساله و وجود دو علامت از علائم فوق به عنوان

تشخيص SBS درنظر كرفته مىشود [Y. V-9].

هم عوامل شخصى و هم عوامل محيطى ممكن است

تعيين كنندههاى SBS باشند. عوامل محيطى عبارتند از: ميزان تهويه، سطح كل تركيبات آلى فرار، رطوبت، روشنايى، صدا و غيره است. در حالى كه عوامل شخصى شامل استرس تر ناشى از كار يا وضعيت اجتماعى-|قتصادى، كيفيت زندگى،

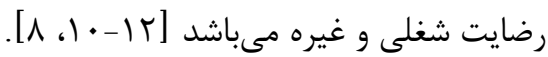

فراوانى علائم SBS و عوامل مرتبط با آن در مطالعات مختلف از جمله در يرستاران بخشهاى مراقبت ويزه بيمارستانهاى آموزشى كرمان شامل عدم تمركز (T/ 9

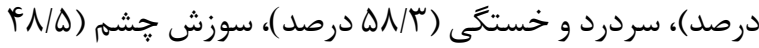
درصد) گزارش شده است [ץ]. در حالى كه در كاركنان شاغل در بيمارستان مصطفى خمينى شهر ايلام شايعترين علائم SBS

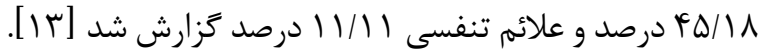
و همكاران در r I Smajlovi'c بيمارستانهاى اسلواكى 9 نشانه SBS كزارش دادند و در 19 درصد آنها ץ تا س علامت SBS مشاهده كردند [4 | [ ]. هر جند كه در مطالعهاى ميزان شيوع SBS در كاركنان بيمارستان Kutahya

زنان T/9 برابر بيشتر از مردان كزارش شد [هـ] بيمارستان يكى از اين ساختمانها است كه يرسنل آن با حضور مستمر در معرض صدمات و خطرات يِيشروى برخوردار هستند. بنابراين شرايط بهبود شرايط محيط كارى باعث ازدياد انخيزه و بهرهورى افراد مىشود [r]. در سيستم
انسانها بيش از • م درصد زمان خود را در محل كار يا در خانه خود صرف مى كنند [ [1]. شرايط فيزيكى و روانى محيط كار ارتباط تنكاتنكى با سلامتى افراد دارد. برخوردارى ساختمان از معيارهاى مطلوب موجب امنيت خاطر و حس آرامش در افراد ساكن در ساختمان مىشود [؟]. به طور كلى، كيفيت هواى داخلى (Indoor air quality; IAQ) خوب براى يك محيط كارى سالم لازم است. مشكلات بهداشتى معمولاً با كيفيت هواى داخلى ضعيف، همراه با مشكلات تنفسى، سوزش جشم، سينوزيت، واكنشهاى آلرزيك، ينومونى و برونشيت مىباشد [ـ]. افراد در تماس با هواى محيط داخلى داراى عكسالعملهاى متفاوتى هستند، بهصورتى كه مىتواند ناراحتىهايى مانند آزردكى دمايى، خفكى هوا و بوهاى نامطبوع، همرجنين علائم غير اختصاصى با علل غيرواضح مانند سندرم ساختمان بيمار (Sick building syndrome; SBS) و بيمارىهاى مرتبط با ساختمان مانند ينومونى ازدياد حساسيتى، آسم مرتبط با ساختمان و لزيونلوزيس را در برگيرد [Y]]. كيفيت هواى داخل ساختمان با علائمى مثل تهوع، سرفه، سردرد، عطسه، تحريك مخاط جشم، گوش و بينى، خارش يوست در ايجاد يك نوع بيمارى به نام SBS دخالت دارد. شدت اين بيمارى با مدت زمان حضور فرد در

ساختمان ارتباط دارد [ع-ه ، r]. يك بيمارى ناشى از ساختمان است كه افراد حاضر SBS در محيط آن داراى وضعيت جسمى و روحى مناسبى تجربه نمى كنند و تغييرات روحى و جسمى شامل سردرد، تهوع، خستخى نامتعارف، عدمتمركز حواس، احساس بوى نامطبوع مىباشد. SBS موجب شكايت كاركنان از كيفيت هواى داخل 
توسط يرستاران بخشهاى مختلف بيمارستان ياسخ و تحويل داده شد، ·r يرسشنامه به دليل عدم جوابدهى كامل از مطالعه كنار كذاشته شدند و در مجموع 凡ץا يرسشنامه كه به نحوه صحيح تكميل شده بودند، مورد تجزيه تحليل قرار

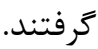

ابزار جمعآورى اطلاعات يرسشنامه استاندارد مرتبط با SBS و كيفيت هواى داخل ساختمان بود. اين يرسشنامه انخليسى توسط Ghaneian و همكاران به فارسى ترجمه شده است و يايايى آن توسط آزمون آلفاى كرونباخ VD/. Fزارش شده است [T]. يرسشنامه حاوى اطلاعات دموكرافيك يرستاران شامل سن، جنسيت، وضعيت تأهل، كل سابقه كارى در بيمارستان، سابقه كار در بخش فعلى، ساعت كار هفتگى، تعداد مراجعين روزانه، تعداد شيفت شب در ماه، و بخش كارى بود.

در يرسشنامه براى شناسايى افراد بيمار، پِاسخ به سؤالات مربوط به علائم سندرم به صورت "بله-اغلب اوقات، بله-كاهى اوقات و نه هر گز" تقسيم بندى شده است و همجزنين يرسيده مىشود كه آيا اين علائم ناشى از محيط كار است؟ (بلى -خير). افرادى كه در اغلب اوقات و كاهى اوقات حداقل يكى از علائم عمومى و نورولوزيك مشتمل بر احساس سنگينى سر، سردرد، تهوع، سرگيجه، و مشكل در تمركز و يك علامت مثبت در تحريك مخاط تنفسى شامل، تحريك و خارش و آبريزش بينى، عطسه، خشكى گلو، سرفه و يا خارش و آبريزش جشه، خشكى و قرمزى يوست صورت، يوسته يوسته شدن و خارش يوست سر و گوش ها، خشكى دست و قرمزى يوست صورت دارند و آن را ناشى از محيط كار مى دانند به عنوان موارد مثبت

سندرم ساختمان بيمار در نظر گرفته شد [ץ].
خدمات بهداشتى، پرستاران نقش مهمى در بهبود خدمات مراقبت و سلامتى ايفاء مىنمايند. بنابراين برطرف نمودن مشكلات اثر كذار بر عملكرد و بهر هورى يرستاران داراى اهميت ويزهاى مىباشد [ع|]. بنابراين هدف از اين مطالعه تعيين فراوانى SBS و عوامل مرتبط با آن در يرستاران بيمارستان على ابن ابى طالب (ع) رفسنجان در سال V9 1 بود.

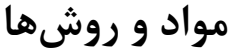

اين مطالعه مقطعى با استفاده از برسشنامه خود گزارش دهى جهت تعيين فراوانى SBS و عوامل مرتبط با آن در يرستاران بيمارستان على ابن ابىطالب(ع) شهر رفسنجان در

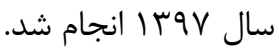
״س از كسب مجوز اخلاق دانشحاه علوم يزشكى رفسنجان (IR.RUMS.REC.1397.113) و يس از توضيح اهداف يزوهش و اين كه شركت در مطالعه به صورت آزادانه و با رضايت است، اقدام به نمونه نفر از يرستاران بخشهاى مختلف بيمارستان به روش سرشمارى وارد مطالعه شدند. به يرستارانى كه با رضايت، حاضر به همكارى در تحقيق بودند، يرسشنامه استاندارد تحويل داده شد. به آنها در خصوص يرسشنامه و اهميت مطالعه توضيحاتى داده شد و به آنها اطمينان داده شد كه اطلاعات به صورت محرمانه خواهد بود و در ضمن يرسشنامه بدون نام و نامخانوادگى تكميل شد. از يرستاران خواسته شد كه اگر در شيفت كارى فرصت مناسب دارند، يرسشنامه را تكميل نمايند و در انتهاى شيفت از آنها تحويل كَرفته شد. در غير اين صورت از آنها خواسته شد كه يرسش نامه را با خود به منزل برده و با تمركز و دقت تكميل نمايند و در شيفت بعدى آن را تحويل دهند. از ها إرسشنامه كه 
ه9 بر هوسى فراوانى سندرم ساختمان بيمار و عوامل مرتبط با آن در يرستاران ...

كه \ץ ا يرستار يرسشنامه استاندارد MM040EA را به نحوه صحيح تكميل نمودند و ميزان ياسخ گويى NV/T درصد بود. فراوانى SBS در يرستاران مورد مطالعه / | ل درصد( • ( نفر)

بود.

در ارزيابى فراوانى علائم SBS مشاهده شد كه 11

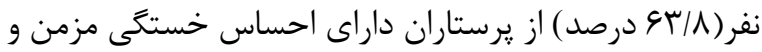
در VV نفر (I/ اله درصد) از آنها خشكى دست و خارش و قرمزى يوست از شايعترين علائم بود. جدول ا، توزيع فراوانى علائم SBS در : يرستاران بيمارستان على ابن ابىطالب (ع)

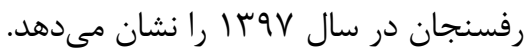

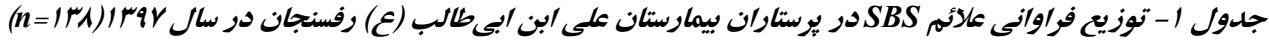

\begin{tabular}{|c|c|c|}
\hline (درصد) تعداد & (درصد) تعداد & علايم سندرم ساختمان بيمار \\
\hline$\Delta \cdot(\Gamma G / T)$ & $\Lambda \Lambda(\mathcal{G} / \Lambda)$ & احساس خستكى مزمن \\
\hline $1 F(9 \cdot 19)$ & $\Delta F(r q / 1)$ & احساس سنكَينى سر \\
\hline $1 \cdots(V Y / \Delta)$ & $r V(T \& \mid \Lambda)$ & تهوع و سركيجه \\
\hline$V V(\Delta \Delta / \Lambda)$ & $G \cdot(F+/ \Delta)$ & مشكل در تمركز \\
\hline$q \vee(V \cdot / r)$ & $(Y)(r q / V)$ & خارش و سوزش حشم \\
\hline $1 \cdot r(V Y / \varphi)$ & TYF $(T Y / G)$ & تحريك شديد و خارش و ابريزش بينى \\
\hline $1 \cdot F(V \Delta / F)$ & $M F(T Y / Q)$ & خس خس و خشكى كلو \\
\hline $1 \cdot r(V / q)$ & $M Y(Y Y / Q)$ & 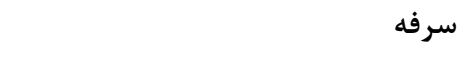 \\
\hline $90(9 N / \Lambda)$ & $\operatorname{Rr}(r \cdot / \mathcal{F})$ & خشكى و قرمزى يوست صورت \\
\hline $9 \Delta(Y V / I)$ & $V \backslash(D) / F)$ & خشكى دست و خارش و قرمزى يوست \\
\hline
\end{tabular}

كارى آنها به ترتيب ع ماه و •r سال بود. مشاركت كنندكان

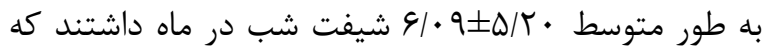
بدون شيفت شب حداقل و ها شيفت شب در ماه حداكثر آن بود. نتايج آزمون آمارى نشان داد بين مشخصات دموكرافيك

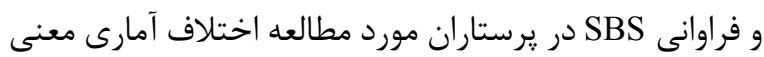

$$
\text { دارى مشاهده نشد (ه> (P> (P). }
$$

نتايج به صورت (درصد) تعد/د/رائه شلداند.
دادها با استفاده از نرم افزار SPSS نسخه \ل و آمارهاى توصيفى (فراوانى، ميانگين و انحراف معيار) و آزمونهاى آمارى استنباطى (آزمون مجذور كاى) تجزيه و تحليل شدند. سطح معنى دارى در آزمونها هـ • • در نظر كرفته شد.

نتايج در اين مطالعه در مجموع له| يرستار دردسترس بودند
نتايج مطالعه نشان داد كه ميانگين و انحراف معيار سن

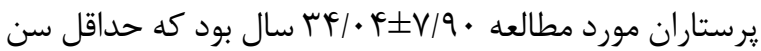

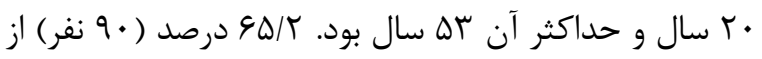
يرستاران شركت كننده در مطالعه زن بودند. ميانكين و انحراف معيار سابقه كارى در بيمارستان يرستاران مورد مطالعه • 9/DF士V/D سال بود كه حداقل و حداكثر سابقه 
جدول r، مقايسه فراوانى SBS برحسب مشخصات

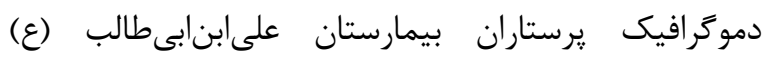

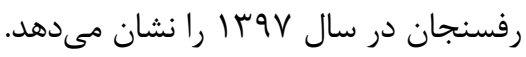

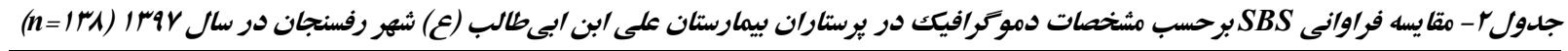
فراوانى سندرم ساختما ن بيمار

Pتغير (درصد) تعداد (درصد) تعداد

\begin{tabular}{|c|c|c|c|c|c|}
\hline & $\wedge(\Gamma \Delta / \cdot)$ & $F r(r q / \varphi)$ & $\Delta \cdot(\Psi G / \Gamma)$ & $<r$. & \\
\hline \multirow{2}{*}{ - MFY } & $10(f \& / 9)$ & $\mathcal{F}(\mathcal{F} T / Q)$ & $G \cdot(\mathbb{E} / \Delta)$ & $r \cdot-r \cdot$ & \multirow[t]{2}{*}{ 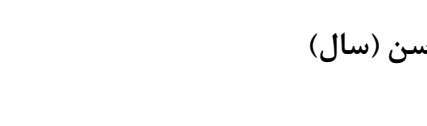 } \\
\hline & $9(T N / I)$ & $19(18 / 9)$ & $r \Lambda(Y \cdot / r)$ & $>r$. & \\
\hline \multirow{2}{*}{$\cdot 11 \cdot 1$} & $I V(\Delta T / I)$ & $V r(9 N / 9)$ & $q \cdot(\varepsilon \Delta / r)$ & 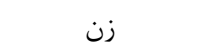 & \multirow{3}{*}{ 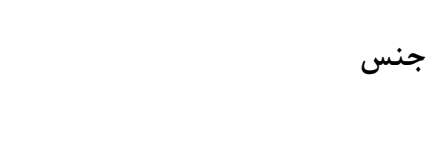 } \\
\hline & $10(\& \varepsilon / q)$ & r & $\forall \wedge(r \mu / \Lambda)$ & مرد & \\
\hline \multirow{2}{*}{$\cdot|9| V$} & $\wedge(T \Delta / \Lambda)$ & $r \cdot(1 / / 9)$ & $r \wedge(T \cdot / r)$ & 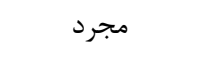 & \\
\hline & $r r(V F / T)$ & $\wedge \varphi(\wedge) / 1)$ & $1 \cdot 9(\vee 9 / \cdot)$ & 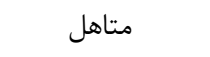 & \multirow[t]{2}{*}{ وضعيت تأهل } \\
\hline- & - & - & $1(\cdot / V)$ & ياسخ داده نشده & \\
\hline \multirow{3}{*}{ - } & TI $(9 \Delta / 9)$ & $V G(V / V)$ & $9 \vee(V \cdot / r)$ & $<1$. & \multirow{3}{*}{ كل سابقه كارى در بيمارستان (سال) } \\
\hline & $\Delta(\mid Q / 9)$ & $\mid V(|9| \cdot)$ & $r r(1 Q / 9)$ & $1 \cdot-r \cdot$ & \\
\hline & $\varepsilon(\mid N / \Lambda)$ & $\|(\mid r / T)$ & $19(14 / \Lambda)$ & $>r$. & \\
\hline \multirow{3}{*}{$\cdot / r \cdot r$} & $r V(\Lambda F / F)$ & $\wedge q(\Lambda ศ / \cdot)$ & $11 \varepsilon(\lambda \& / 1)$ & $<1$. & \multirow{3}{*}{ سابقه كارى در بخش فعلى (سال) } \\
\hline & $\Delta(\mid Q / 9)$ & $11(1 \cdot / r)$ & $19(11 / 9)$ & $1 \cdot-r \cdot$ & \\
\hline & $\cdot(\cdot / \cdot)$ & $\varphi(\Delta / V)$ & $\varphi(F / r)$ & $>r$. & \\
\hline \multirow{3}{*}{ - / 199} & $I Y(T V / \Delta)$ & $F \varphi(f / / \Delta)$ & $\Delta \varphi(\varphi \cdot 19)$ & $<\Delta$ & \multirow{3}{*}{ تعداد شيف شب در ماه } \\
\hline & $\| \Lambda(\Delta \& / \widetilde{r})$ & $\Delta F(\Delta I / \cdot)$ & $V T(\Delta T / T)$ & $\Delta-1$. & \\
\hline & $r(\varepsilon / r)$ & $\wedge(V / \Delta)$ & $1 \cdot(V / r)$ & $>1$ & \\
\hline \multirow{3}{*}{$\cdot / 491$} & $\|(\Gamma \Delta / \Psi)$ & $r \wedge(r \& / 9)$ & $r q(r \Lambda / r)$ & 1 † ساعت & \multirow{3}{*}{ تعداد ساعت كارى در هفته } \\
\hline & $1 \cdot(\Gamma r / T)$ & $\Delta \cdot\left(F^{\mathcal{N}} / \mathrm{I}\right)$ & $G \cdot(F r / Q)$ & 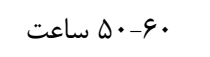 & \\
\hline & $1 \cdot(r T / T)$ & $T \varphi(T \Delta / \cdot)$ & MG $(Y \varphi \mid \cdot)$ & $>9$. & \\
\hline \multirow[t]{2}{*}{-} & & - & $r(T / T)$ & ياسخ داده نشده & \multirow{4}{*}{ عداد بيمار مراجعه كننده به بخش } \\
\hline & $9(\mid N / \Lambda)$ & $r V(r r / q)$ & $F r(\Psi, / T)$ & $<10$ & \\
\hline \multirow[t]{2}{*}{ - MTY } & $r r(V / / 9)$ & Q) (DV/G) & $\Lambda F(\varepsilon \cdot / \Lambda)$ & $1 \Delta-r \cdot$ & \\
\hline & $r(9 / \Gamma)$ & $\wedge(V / \Delta)$ & $11(N / \cdot)$ & $>r$. & \\
\hline \multirow{4}{*}{$\cdot / r \wedge \Delta$} & $F(\mid Y / \Delta)$ & $19(10 / 1)$ & $r \cdot(\mid F / \Delta)$ & 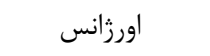 & \multirow{4}{*}{ بخش كارى } \\
\hline & $\Delta(\mid \Delta / 9)$ & $T \varphi(T Y / \Delta)$ & $M(Y T / Q)$ & 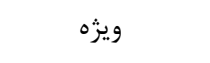 & \\
\hline & $r(9 / 4)$ & $\mid \Lambda(|V| \cdot)$ & $r \mid(\mid Q / r)$ & اتاق عمل & \\
\hline & $r \cdot(G T / Q)$ & $\mathcal{H}(\mathcal{E} \Psi / \mathcal{F})$ & $G G(\mathbb{E V} / \Lambda)$ & عمومى و تخصصى & \\
\hline
\end{tabular}


ه9

آزمون مجذور كاى، 0.>>>P اختلاف معنىد/ر

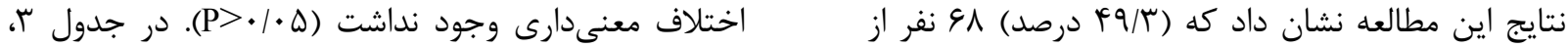

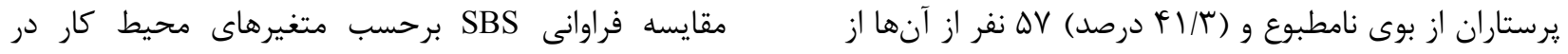
سر و صداى محيط كار، اغلب اوقات شكايت داشتند. بين يرستاران بيمارستان على ابن ابىطالب (ع) رفسنجان در سال

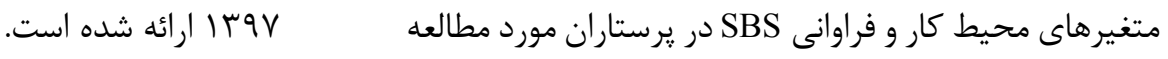

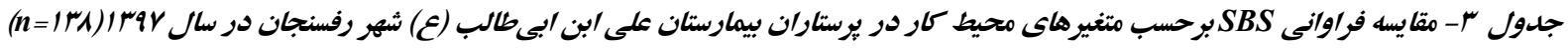

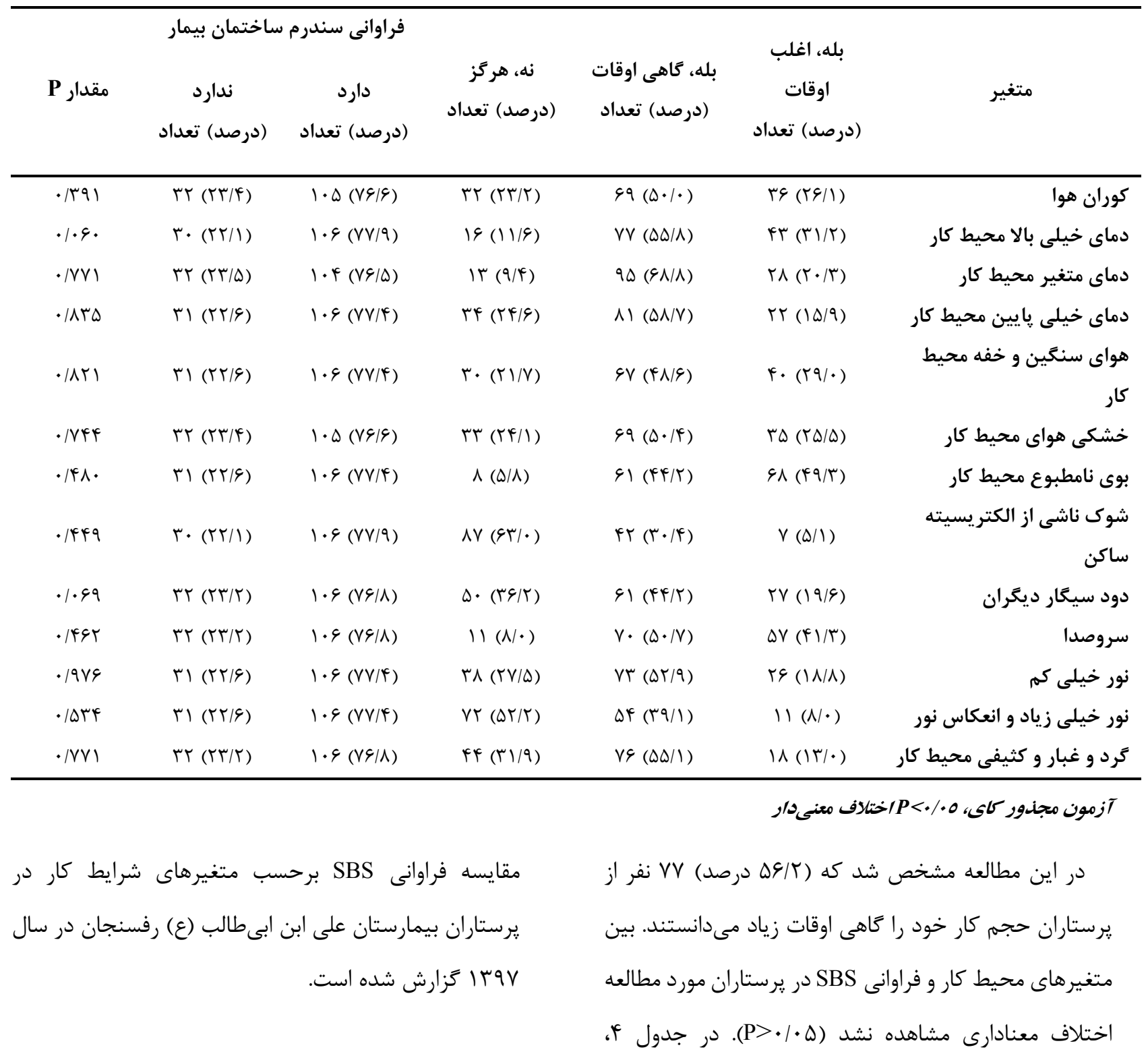

دوره 19، شماره ع، سال 1r9919

مجله دانشگاه علوم يزشكى رفسنجان 


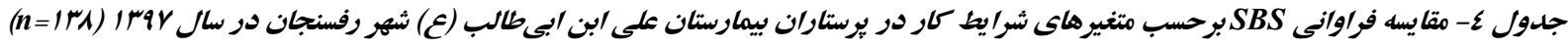

\begin{tabular}{|c|c|c|c|c|c|c|c|}
\hline مقدار P & ساختمان بيمار & فراوانى سندر & نه، هركز & نه، بندرت & 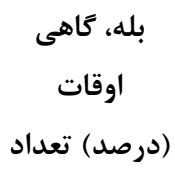 & (درصد، هميشه تعداد & متغير \\
\hline$\cdot / \& V r$ & $r r(T r / T)$ & $1.9(V \& \mid \Lambda)$ & $1 \cdot(V / r)$ & $r \&(\mid N / \Lambda)$ & $\varepsilon \psi(\uparrow \& / \Delta)$ & TA $(Y V / Q)$ & كار جذاب و مهيج \\
\hline$\cdot \mid \cdot v 1$ & $r T(Y r / Y)$ & $1 \cdot \omega(\vee \& \mid \varphi)$ & $V(\Delta / 1)$ & $r V(T V / \cdot)$ & $V V(\Delta G / T)$ & $19(11 / \mathrm{V})$ & حجم كارى زياد \\
\hline$\cdot 1 \ldots$ & $\Psi(r r / \Lambda)$ & $1 \cdot \Delta(V V / r)$ & $\Delta(\tau / V)$ & $r \Lambda(T \cdot \mid \varphi)$ & $V)(\Delta T / T)$ & $r T(T r / \Delta)$ & 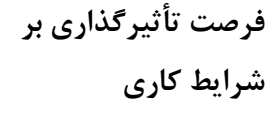 \\
\hline$\cdot / 1 \cdot r$ & $r T(Y T / T)$ & $1.9(\mathrm{~V} / \mathrm{N})$ & $V(\Delta / 1)$ & $q(\xi / 4)$ & $q \vee(F \wedge / G)$ & $\Delta \Delta(\Gamma q / q)$ & مشكلاتى كمكاران در حل \\
\hline
\end{tabular}

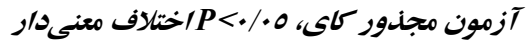

نتايج مطالعه حاضر نشان داد كه احساس خستخى مزمن و

خشكى دست، خارش و قرمزى يوست از شايعترين علائم در

يرستاران داراى SBS بود. بيشترين علائم SBS در مطالعات

ديكر شامل Vafaeenasab و همكاران خستخى مزمن 9/9

درصد و سردرد س/r/ درصد [IV]]، در مطالعه Ghaneian و

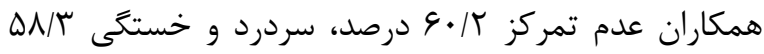
درصد [ץ]، در مطالعه Chang و همكاران تحريك شديد و خارش و آبريزش بينى (Nasal symptoms) ع 4 درصد و خارش و سوزش خشم (Eye symptoms) به درصد [1/]،

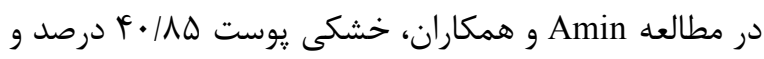
آبريزش بينى اب درصد [V] كزارش شدند. دلايل تفاوت اين مطالعه با ساير مطالعات مىتوان به فشار كارى يا شيفتهاى كارى زياد، ساعات كارى طولانىتر، در معرض تماس با مواد شيميايى مانند مواد ضدعفونى كننده، بوى نامطبوع محيط كار، حساسيت افراد، تهويه نامناسب محيط كار نسبت يافتهاى اين مطالعه نشان داد كه فراوانى SBS در يرستاران مورد مطالعه بالا است. فراوانى SBS در ڤيرستاران

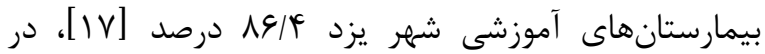

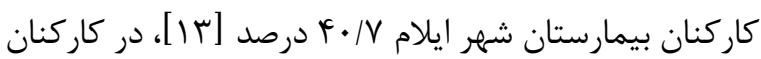

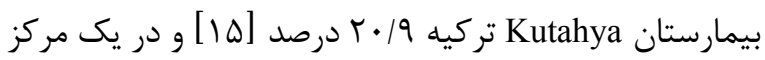
يزشكى تايوان N\& درصد [11] تزارش شد. از طرفى Motesaddi

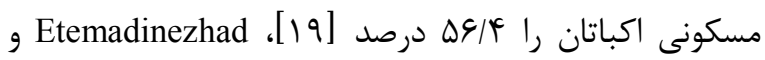
همكاران ميزان شيوع SBS در كاركنان يك بانك استان مازندران را Vq/\& درصد [\&] ززارش كردند. تفاوت بين مطالعات فوق با اين مطالعه در طراحى و نوع ساختمان، عوامل فيزيكى و شيميايى محيط كار (روشنايى، صدا، تجهيزات، كازها و بخارات)، تهويه، نوع كار افراد، رضايتمندى از شغل و حساسيت فردى مىباشد. 
شيميايى (COrmaldehyde ،OCs ، (باكترىها، قارجها) محيط كار و مقايسه با دادههاى حاضر به علت نبود امكانات و تجهيزات مىباشد كه يِيشنهاد مىشود براى انجام مطالعات آينده علاوه بر اندازهيرى يارامترهاى فيزيكى، شيميايى و بيولوزيكى محيط كار از يرسشنامههاى رضايت شغلى، كيفيت خواب نيز استفاده شود.

\section{نتيجهل}

نتايج مطالعه حاضر نشان داد كه فراوانى علائم SBS در يرستاران بالا بود كه از علل عمده آن تهويه ناكافى و بوى نامطبوع محيط كار، حجم بالاى كار مىباشد. با ايجاد سيستم تهويه مطبوع در بيمارستان مىتوان موجب كاهش علائم SBS شد كه اين امر بر عملكرد و بهرهورى يرستاران اثركذار خواهد بود كه در نتيجه موجب بهبود كيفيت خدمات ارائه شده توسط

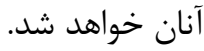

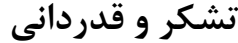

اين يزوهش بر كرفته از طرح تحقيقاتى با عنوان "بررسى فراوانى

علائم سندرم ساختمان بيمار در يرستاران بيمارستان على ابن ابى ليى طالب(ع) شهر رفسنجان در سال Vوץו" است كه در شوراى يزوهشى دانشكاه علوم يزشكى و خدمات بهداشتى درمانى رفسنجان با كد 9VTrD به تصويب رسيده است. نويسندكان از معاونت تحقيقات و فناورى دانشكاه علوم يزشكى رفسنجان به جهت حمايت مالى از اين طرح و همجنين از يرستاران محترم بيمارستان على ابن ابىطالب (ع) شهر رفسنجان به خاطر شركت در اين يزوهش و تكميل صادقانه يرسشنامه تشكر و قدردانى مىنمايند. .
البته شايد يكى از دلايل احساس خستگى مزمن در يرستاران مورد مطالعه مربوط به كيفيت پايين خواب آنها باشد. جنانجه نتايج مطالعهاى در دانشعاه علوم يزشكى رفسنجان نشان داد كه 9N/9 درصد از يرستاران شيفت در كردش مورد مطالعه داراى كيفيت خواب پايين بودند [.r]. بنابراين زمانى كه جرخه خواب و بيدارى انسان مختل شود، ساير عملكردهاى فيزيولوزيك بدن نيز تغيير مى كند. در اثر محروميت از خواب، هورمون آدرنالين به ميزان بيشترى وارد خون مىشود، بنابراين فرد احساس خستكى و افسردىى بيش ترى مى كند و تمركز وى كاهش مىيابد [1r]. خشكى دست و خارش و قرمزى يوست در يرستاران مورد مطالعه به دليل استفاده از دستكش لاتكس يا مواد ضدعفونى كننده مىباشد. دستكشهاى لاتكس به علت عملكرد بالا و محافظت كنندگى مناسب در زمان ارائه خدمات درمانى به وفور استفاده مىشود و جهت تسهيل در يوشيدن و جلوكيرى از به هم جسبيدن دستكش آن را آغشته به يودر مخصوص مىنمايند كه اين يودر موجب حساسيت يوستى و تنفسى مى

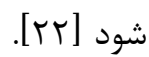
در اين مطالعه بين فراوانى SBS و ويزگىهاى فردى يرستاران اختلاف آمارى معنىدارى مشاهده نشد هر جند كه در برخى مطالعات فراوانى SBS در زنان بيشتر از مردان

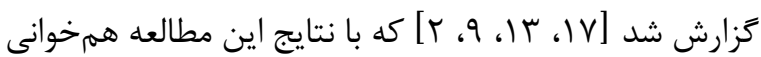

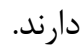
از محدويتهاى مطالعه حاضر، عدم اندازمخيرى پارامترهاى فيزيكى (صدا، دما، رطوبت، سرعت جريان هوا، روشنايى)،

\section{References}


[1] Norhidayah A, Chia-Kuang L, Azhar MK, Nurulwahida S. Indoor Air Quality and Sick Building Syndrome in Three Selected Buildings. Procedia Engineg 2013; 53: 93-8.

[2] Ghaneian M, Morovvati Sharif Abad M, Ehrampoosh M, Haj Hosseini M. Prevalence of symptoms of sick building syndrome and its associated factors in intensive care nurses in Kerman University of medical sciences educational hospitals. Occupational Medicine Quart j 2013; 5(3): 49-57. [Farsi]

[3] Syazwan A, Rafee BM, Juahir H, Azman A, Nizar A, Izwyn Z, et al. Analysis of indoor air pollutants checklist using environmetric technique for health risk assessment of sick building complaint in nonindustrial workplace. Drug, healthcare and patient safety 2012; 4: 107-26.

[4] Etemadinezhad S, Esmaili Naftchali N, Alizade Larimi A, Yazdani Charati J. Prevalence of Sick Building Syndrome in Bank Employees and its Relationship with Job Satisfaction and Some Environmental Factors. J Mazandaran Univ Med Sci 2017; 27(152): 153-64. [Farsi]

[5] Jafari MJ, Khajevandi AA, Mousavi Najarkola SA, Yekaninejad MS, Pourhoseingholi MA, Omidi L, et al.
Association of Sick Building Syndrome with Indoor Air Parameters. Tanaffos 2015; 14(1): 55-62.

[6] Saijo Y, Nakagi Y, Ito T, Sugioka Y, Endo H, Yoshida T .Dampness, food habits, and sick building syndrome symptoms in elementary school pupils. Environ Health Prev Med 2010; 15(5): 276-84.

[7] Amin NDM, Akasah ZA, Razzaly W. Architectural Evaluation of Thermal Comfort: Sick Building Syndrome Symptoms in Engineering Education Laboratories. Procedia Soc Behav Sci 2015; 204: 1928.

[8] Jafari MJ, Khajevandi AA, Mousavi Najarkola SA, Pourhoseingholi MA, Omidi L, Zarei E. Symptoms of Sick Building Syndrome in Office Workers of Petroleum Industry Health Organization. J. Occup. Hyg. Eng 2015; 2(1): 66-7. [Farsi].

[9] Kholasezadeh G, Mirmohammadi Meybodi S, Mehrparvar A, Fallah Tafti, Abedinzadeh M, Nourani Yazdi F. Assessment of sick building syndrome among office workers in Shahid Sadoughi University of medical sciences in 2008. IOH 2011; 8(1): 70-6. [Farsi]

[10] Jung CC, Liang HH, Lee HL, Hsu NY, Su HJ. Allostatic load model associated with indoor environmental 
quality and sick building syndrome among office workers. PloS one 2014; 9(4): e95791.

[11] Lu CY, Tsai MC, Muo CH, Kuo YH, Sung FC, Wu CC. Personal, Psychosocial and Environmental Factors Related to Sick Building Syndrome in Official Employees of Taiwan. Int. J. Environ. Res. Public Health 2017; 15(1): 1-9.

[12] Zhang X, Sahlberg B, Wieslander G, Janson C, Gislason T, Norback D. Dampness and moulds in workplace buildings: associations with incidence and remission of sick building syndrome (SBS) and biomarkers of inflammation in a 10 year follow-up study. Sci Total Environ 2012; 430: 75-81.

[13] khosravinejad A, Sayehmiri K, Kazemy M, Shirmohamadi N, Abyaz M, Kurd N. Evaluation of Sick Building Syndrome prevalence among Mustafa Khomeini hospital staff in Ilam, 2015. Sjimu 2018; 25(5): 1-9.[Farsi]

[14] Smajlovi'c SK, Kukec A, Dovjak M. Association between sick building syndrome and indoor environmental quality in Slovenian hospitals: a crosssectional study. Int J Environ Res Public Health 2019; 16(17): 1-18.
[15] Arikan I, Tekin ÖF, Erbas O. Relationship between sick building syndrome and indoor air quality among hospital staff. Med Lav 2018; 109(6): 435-43.

[16] Najafi Ghezeljeh T, Sedghian H, Mohaddes Ardabili F, Rezaei Loieh H. Effect of Benson Relaxation on Fatigue of Nurses Working in Intensive Care Units. J. client- centered nurs. care 2015; 1(4): 211-7.

[17] Vafaeenasab MR, Morowatisharifabad MA, Ghaneian MT, Hajhosseini M, Ehrampoush MH. Assessment of sick building syndrome and its associating factors among nurses in the educational hospitals of Shahid Sadoughi University of Medical Sciences, Yazd, Iran. Glob J Health Sci 2014; 7(2): 247-53.

[18] Chang CJ, Yang HH, Wang YF, Li MS. Prevalence of sick building syndrome-related symptoms among hospital workers in confined and open working spaces. Aersol Air Qual Res 2015; 15: 2378-84.

[19] Motesaddi S, Sheikhmohammadi A, Sardar M, Jayboiee S, Akbarpour S. Investigation of Sick Building Syndrome Symptoms in Inhabitants of Ekbatan Town. J Mashhad Univ Med Sci 2011; 54(4): 224-9. [Farsi]

[20] Khajeh Hosseini S, Sayadi A, Mobini Lotfabad M, Heidari S. Sleep Quality among Shift-working Nurses in the Hospitals of Rafsanjan City, Iran, in 2018. Health Develop J 2019; 8(2): 141-51. [Farsi] 
[21] Khajeh Hosseini S, Sayadi A, Mobini Lotfabad M, Heidari S. The effect of Benson's relaxation technique on sleep quality among shift-working nurses in hospitals. Hayat 2020; 24(4): 415-42. [Farsi]
[22] Rezaee M, Ghasemi M, Joneidi Jafari N. Latex glove allergy in dental workers: complications and predisposing factors. Tehran Univ Med J 2008; 65(13): 42-48. [Farsi]. 
Y.9 بررسى فراوانى سندرم ساختمان بيمار و عوامل مرتبط با آن در برستاران ....

\title{
Frequency of Sick Building Syndrome and Its Related Factors in Nurses at Ali Ibn Abitaleb Hospital in Rafsanjan City 2018: A Cross-Sectional Study
}

\author{
H. Khodadadi ${ }^{1}$,M. Mobini Lotfabad ${ }^{2}$,F. Shykh Ali Babaie Mahani ${ }^{3}$, M. Mahbobi rad $^{4}$, M. \\ AsadPour $^{5}$, H. Eslami ${ }^{6}$, Sh. Khajeh Hosseini ${ }^{7}$, H. Bagherinasab ${ }^{8}$
}

Received: 08/07/2020 Sent for Revision: 22/07/2020 Received Revised Manuscript: 24/08/2020 Accepted: 25/08/2020

Background and Objectives: Sick building syndrome (SBS) is a building-related illness in which people in the environment do not experience proper physical and mental well-being. Mental and physical changes include headache, nausea, abnormal fatigue, lack of concentration, sensation of an unpleasant odor. Thus, the aim of this study was to investigate the frequency of SBS and its related factors in nurses at Ali Ibn Abitaleb hospital in Rafsanjan City in 2018.

Materials and Methods: This cross-sectional study was performed using standard MM040EA questionnaire related to SBS and indoor air quality at Ali Ibn Abitaleb hospital in Rafsanjan city in 2018. 285 nurses in different wards of the hospital were entered the study using census method. Data were analyzed by descriptive statistics and chi-square test.

Results: The mean \pm standard deviation of age for participating nurses was 34.04 \pm 7.90 years. Fatigue $88(63.8 \%)$, dry hands and itching and red skin $71(51.4 \%)$ were the most frequent symptoms of SBS among the nurses. 68 (49.3\%) nurses complained of unpleasant odors of the workplace every week, and 77 (56.2\%) nurses felt their workload was sometimes high. Demographic characteristics, work environment and working conditions did not show any statistically significant difference with the frequency of SBS ( $\mathrm{p}>0.05)$.

Conclusion: Due to the high frequency of SBS in hospital nurses and its effects on performance and productivity, it is necessary to re-engineer the hospital environment and improve the work environment, especially ventilation of hospital wards.

Key words: Sick building syndrome, Work environment, Nurses, Hospital wards, Rafsanjan

Funding: This study was funded by Rafsanjan University of Medical Sciences.

Conflict of interest: None declared.

Ethical approval: The Ethics Committee of Rafsanjan University of Medical Sciences approved the study (IR.RUMS.REC.1397.113).

How to cite this article: Khodadadi H, Mobini Lotfabad M, Shykh Ali Babaie Mahani F, Mahbobi rad M, AsadPour M, Eslami H, Khajeh Hosseini Sh, Bagherinasab H. Frequency of Sick Building Syndrome and Its Related Factors in Nurses at Ali Ibn Abitaleb Hospital in Rafsanjan City 2018: A Cross-Sectional Study. J Rafsanjan Univ Med Sci 2020; 19 (6): 591-602. [Farsi]

1- Assistant Prof. of Health in Disasters and Emergencies, Dept. of Health Promotion and Education, School of Health, Rafsanjan University of Medical Sciences, Rafsanjan, Iran, ORCID: 0000-0002-4044-1180

r- Instructor of Environmental Health Engineering, Dept. of Environmental Health Engineering, School of Health, Rafsanjan University of Medical Sciences, Rafsanjan, Iran, ORCID: 0000-0003-2779-531X

(Corresponding Author) Tel: (034) 31315000, Fax: (034)31315000,E-mail: mobinilk@gmail.com

r- BSc in Environmental Health Engineering, Dept. of Environmental Health Engineering, School of Health, Rafsanjan University of Medical Sciences, Rafsanjan, Iran, ORCID: 0000-0003-1307-3308

E- PhD Student of Health Promotion and Education, Dept. of Health Promotion and Education, School of Health, Rafsanjan University of Medical Sciences, Rafsanjan, Iran, ORCID: 0000-0003-0442-3601

a- Assistant Prof. of Health Promotion and Education, Dept. of Health Promotion and Education, School of Health, Rafsanjan University of Medical Sciences, Rafsanjan, Iran, ORCID: 0000-0003-0442-3601

7- Assistant Prof. of Environmental Health Engineering, Dept. of Environmental Health Engineering, School of Health, Rafsanjan University of Medical Sciences, Rafsanjan, Iran, ORCID: 0000-0001-5137-4764

Y-MSc in Critical Care Nursing, Ali Ibn Abitaleb Educational and Tretment Hospital, Rafsanjan University of Medical Sciences, Rafsanjan, Iran, ORCID: 0000-0001-9585-7311

A- MSc in Community Health Nursing, Ali Ibn Abitaleb Educational and Tretment Hospital, Rafsanjan University of Medical Sciences, Rafsanjan, Iran, ORCID: 0000-0001-5137-4764

دوره 91، شماره \&، سال 99"1

مجله دانشگاه علوم يزشكى رفسنجان 